\title{
Growth and development of the reproductive organs of female breeding ostriches
}

\author{
T.R. Olivier ${ }^{1,2}$, T.S. Brand ${ }^{1,2 \#}$ and R.M. Gous ${ }^{3}$ \\ ${ }^{1}$ Elsenburg Institute for Animal Production, Department of Agriculture, Western Cape, Private Bag X1, \\ Elsenburg 7607, South Africa \\ ${ }^{2}$ Department of Animal Sciences, University of Stellenbosch, Private Bag X1, Matieland 7602 \\ ${ }^{3}$ Animal and Poultry Science, School of Agricultural Sciences and Agribusiness, \\ University of KwaZulu-Natal, Private Bag X01, Scottsville 3209, South Africa
}

\begin{abstract}
A study was conducted to determine the growth rate of the reproductive organs of breeding female ostriches, which may be used in a prediction model for estimating nutrient requirements of breeders. Forty breeding female ostriches were sampled over an eight week period (five per week) starting at the onset of the breeding season. The ovary and oviducts were collected and weighed at each slaughter interval. No significant trend in the weight of the oviduct of the ostriches could be observed over the $49 \mathrm{~d}$ period, this weight being highly correlated with the body weight of the ostrich, whereas the ovary weight tended to be correlated with the time after the onset of the breeding period, although the variation in weights both within and between weights was very high. The variation in the weight of the ovary probably reflects differences in the laying pattern of individuals, and this lends itself to simulating the ovulatory cycle and consequently gaining a better understanding of the process, which would in turn aid in determining the requirement for the nutrients responsible for the growth of the ova.
\end{abstract}

Keywords: Growth, modelling

\#Corresponding author; E-mail address:tersb@elsenburg.com

\section{Introduction}

The daily intake of nutrients to meet the requirements for maintenance, growth and egg production are well defined for broilers and laying hens, but this is not the case with breeding ostriches. Whereas the protein and amino acid requirements for egg production in breeding ostriches determined by Du Preez (1991) were based on the weight of the egg and the bird, this approach has been shown to be less accurate than when the production requirements are based on the composition of the egg, and the maintenance requirements on the body protein content of the bird (Emmans \& Fisher, 1986). Furthermore, Gous \& Nonis (2009) have described the basis for calculating the nutrient requirements for egg production, these being based on the pattern of laying, which is in turn based on the internal cycle length of the hen, and the weights of the yolk and albumen, which differ as the hen ages. The calculations by Du Preez (1991) were based on the assumptions that the breeding ostrich will lay an egg every second day and eat $2 \mathrm{~kg}$ feed per day. A study by Olivier et al (2009) revealed that female birds can consume up to $3.7 \mathrm{~kg}$ feed per day in an ad libitum situation. Under controlled conditions birds are fed only $2.5 \mathrm{~kg}$ feed/d (Brand \& Gous, 2006). Each female produces between 40 and 47 eggs per season (Brand et al., 2002).

When calculating the nutrient requirements of the bird during the period immediately prior to the laying of the first egg it is necessary to account for the growth of the oviduct and ovary. Bowmaker \& Gous (1989) studied the growth of the liver, ovary and oviduct of broiler breeder pullets to calculate the dietary concentration of protein, lysine, methionine and tryptophan necessary to meet the requirements of these birds for maintenance and growth between the ages of 20 and 30 weeks. Different treatments were used to study the rate of development of the oviduct and ovary over time, but growth was the same in all treatments. The Gompertz growth curve fitted the data adequately.

Breeding ostriches need adequate daily intakes of protein for the growth of the reproductive organs. It is possible that reproductive potential is dependent on the growth rate of these organs, although this theory is not supported by some literature (Williams, 2005). Lambrechts (2006) reported that the reproductive ability of the ostrich is dependent on nutrition, behaviour, management and physiological health. Roland et al. 
(1974) stated that the weight of the ovary and oviduct of laying hens is reduced when the dietary calcium supply is less than $0.5 \mathrm{~g}$ calcium $/ \mathrm{kg}$ food, emphasizing the importance of calcium on the reproductive performance of the laying hen.

In this study, the growth rate of the reproductive organs of the breeding female ostrich was investigated in order to gather data for the development of a model of the nutrient requirements of breeding ostriches (Gous \& Brand, 2008).

\section{Material and Methods}

Forty female breeding ostriches were sacrificed over a period of eight weeks at a rate of five per week. The first group was sacrificed on the day of onset of the annual breeding season, when males are placed with the females. The ages of the birds varied between four and 12 years. The ovary and oviduct were removed from each bird and weighed, using a standard scale. The vagina of each oviduct was removed prior to weighing, since it is believed that this part of the oviduct would not vary in weight between the reproductive and non-reproductive states.

An ANOVA was performed on the data using the software programme, Statgraphics (2005), and simple linear regressions were fitted using Genstat (2008).

\section{Results and Discussion}

The mean weights of the reproductive organs, at weekly intervals from the start of the breeding season, are given in Table 1 together with their standard errors. The observations within and between each interval were extremely variable making it impossible to fit Gompertz growth curves to the data, as had been accomplished with broiler breeders (Bowmaker \& Gous, 1989).

For the oviduct, there was no relationship between the weight of the oviduct and the age of the bird or days after mating, but there was a highly significant correlation with body weight (regression coefficient $=$ $18.65 \pm 5.54 \mathrm{~g} / \mathrm{kg}$ body weight, $\mathrm{P}<0.01$ ).

The weight of the ovary was not correlated with age or body weight, but was correlated with days after mating (26.4 $\pm 11.64 \mathrm{~g} / \mathrm{d}, \mathrm{P}<0.05)$. The rate at which the ovary weight increases after the start of the mating period might be expected to show a curvilinear or exponential trend, reaching a peak and then flattening off, but the data do not support this.

Table 1 Mean oviduct and ovary weights, with standard errors (s.e.), of ostriches at weekly intervals from the onset of the breeding season

\begin{tabular}{ccccc}
\hline $\begin{array}{l}\text { Days after onset of } \\
\text { breeding season }\end{array}$ & \multicolumn{2}{c}{ Oviduct weight (g) } & \multicolumn{2}{c}{ Ovary weight (g) } \\
mean & s.e. & mean & s.e. \\
\hline 0 & 516 & 279 & 513 & 363 \\
7 & 932 & 192 & 1394 & 198 \\
14 & 694 & 475 & 2030 & 1898 \\
21 & 484 & 298 & 775 & 717 \\
28 & 813 & 487 & 2046 & 1681 \\
35 & 853 & 516 & 1744 & 1332 \\
42 & 842 & 513 & 1625 & 1124 \\
49 & 868 & 315 & 2399 & 942 \\
& & & & \\
\hline
\end{tabular}

The variation observed in these organs is probably due to the fact that egg production is highly variable in breeding female ostriches. It may be speculated that female birds with a high predicted breeding value for egg production would have higher weights for the reproductive organs, while birds with a low predicted breeding value would consequently have lower weights. The variation in ovary weight reflects differences in the number of developing ova, which would be expected to be highly variable in this species. 
Oviduct weights of birds in an immature sexual state, obtained either before the onset of the first laying period or midway between successive breeding periods, would give a better indication of the extent to which the oviduct would need to grow to reach a sexually mature state. Similarly, the weight of the ovary prior to the development of ova would be a useful measure, to which the weights of the developing ova could be added to determine the nutrient requirements for the growth of these ova. To date, the ovulatory cycle of the female ostrich has not been studied mathematically, and this would be a useful exercise in determining the nutrient requirements for egg production in this species.

\section{Conclusion}

No significant trend in the weight of the oviduct of the ostriches could be observed over the $49 \mathrm{~d}$ period, this weight being highly correlated with the body weight of the ostrich, whereas the ovary weight tended to be correlated with the time after the onset of the breeding period, although the variation in weights both within and between weights was very high. The variation in the weight of the ovary probably reflects differences in the laying pattern of individuals, and this lends itself to simulating the ovulatory cycle and consequently gaining a better understanding of the process, which would in turn aid in determining the requirement for the nutrients responsible for the growth of the ova.

\section{References}

Bowmaker, J.E. \& Gous, R.M., 1989. Quantification of reproductive changes and nutrient requirements of broiler breeder pullets at sexual maturity. Br. Poult. Sci. 30, 663-675.

Brand, T.S. \& Gous, R.M., 2006. Feeding Ostriches. In: Feeding in Domestic Vertebrates: From Structure to Behaviour. Ed. Bels, V., CAB International, Wallingford, England. pp. 136-155.

Brand, Z., Brand, T.S. \& Brown, C.R., 2002. The effect of dietary and protein levels during a breeding season of ostriches (Struthio camelus domesticus) on production the following season. S. Afr. J. Anim. Sci. 32, 226-230.

Du Preez, J.J., 1991. Ostrich nutrition and management. In: Recent Advances in Animal Nutrition in Australia. Ed. Farrell, D.J., University of New England, Armidale, Australia. pp. 278-291.

Emmans, G.C. \& Fisher, C., 1986. Problems in nutritional theory, Poultry Science Symposium No.19. In: Nutrient Requirements of Poultry and Nutritional Research. Eds Fisher, C. \& Boorman, K.N., Butterworths, London. pp. 9-39.

GenStat 2008. GenStat $11^{\text {th }}$ Edition, VSN International. Hemel Hempstead U.K.

Gous, R.M. \& Brand, T.S., 2008. Developing simulation models for food intake and growth of ostriches, $4^{\text {th }}$ International Ratite Science Symposium, 1-4 July 2008, Brisbane, Australia.

Gous, R.M. \& Nonis, M.A., 2009. Modelling egg production and nutrient responses in broiler breeder hens. J. Agic. Sci. (in Press).

Lambrechts, H., 2006. Volstruishandleiding. Department of Agriculture: Western Cape \& South African Ostrich Business Chamber. pp. 106-131.

Olivier, T.R., Brand, T.S. \& Brand, Z., 2009. Production and the effect of dietary energy level on the feed intake of breeding ostriches. South Africa Society of Animal Science's $43^{\text {rd }}$ Congress, 28-30 July 2009, Bergville, South Africa.

Roland, D.A., Sloan, D.R., Wilson, H.R. \& Harms, R.H., 1974. Relationship of calcium to reproductive abnormalities in the laying hen (Gallus domesticus). J. Nutr. 104, 1079-1085.

Williams, T.D., 2005. Mechanisms underlying the costs of egg production. Biosci. 55.1, 39-48. 